\title{
COVID-19 induced liver function abnormality associates with age
}

Research Paper

\author{
Shasha $\mathrm{Li}^{1,}{ }^{*}$, Jinsong $\mathrm{Li}^{1,}{ }^{,}$, Zhenhua Zhang${ }^{2}$, Lin Tan${ }^{1}$, Tuo Shao ${ }^{3}$, Ming $\mathrm{Li}^{1}$, Xiuyong $\mathrm{Li}^{4}$, Jacinta A. \\ Holmes 5 , Wenyu Lin ${ }^{3}$, Mingfeng Han 6 \\ ${ }^{1}$ Department of Hepatology, The Second People's Hospital of Fuyang, Fuyang 236015, Anhui Province, P.R. China \\ ${ }^{2}$ Department of Hepatology, The Second Hospital of Anhui Medical University, Hefei 236015, Anhui Province, P.R. \\ China \\ ${ }^{3}$ Liver Center and Gastrointestinal Division, Department of Medicine, Massachusetts General Hospital, Harvard \\ Medical School, Boston, MA 02114, USA \\ ${ }^{4}$ Blood Purification Center, The Second People's Hospital of Fuyang, Fuyang 236015, Anhui Province, P.R. China \\ ${ }^{5}$ Department of Gastroenterology, St Vincent's Hospital, University of Melbourne, Fitzroy 3065, VIC, Australia \\ ${ }^{6}$ Department of Respiratory, The Second People's Hospital of Fuyang, Fuyang 236015, Anhui Province, P.R. China \\ *Co-first authors
}

Correspondence to: Wenyu Lin, Jacinta A. Holmes, Xiuyong Li, Mingfeng Han; email: wlin1@mgh.harvard.edu, jacinta.holmes@svha.org.au, Ixy8726@126.com, fyhmf@163.com

Keywords: COVID-19, age, liver abnormality, severe, critical patient

Received: May 12, $2020 \quad$ Accepted: July 6, 2020

Published: July 28, 2020

Copyright: Li et al. This is an open-access article distributed under the terms of the Creative Commons Attribution License (CC BY 3.0), which permits unrestricted use, distribution, and reproduction in any medium, provided the original author and source are credited.

\section{ABSTRACT}

Background: Coronavirus disease 2019 (COVID-19) is a novel infectious disease that may cause fever, dry cough, fatigue and shortness of breath. The impact of COVID-19 on liver function is not well described.

Results: We found that the overall frequency of LFT abnormality was $17.6 \%$. Frequency of LFT abnormality was significantly greater in patients with severe/critical (SC) COVID-19 compared to those with mild/moderate (MM) COVID-19 (32.4\% vs $11.6 \%, p=0.011)$. Among patients with LFT abnormality, the median age was significantly higher in the SC group compared to the MM group (52 vs 39 years, $p=0.021$ ).

Conclusion: COVID-19 is frequently associated with mild liver function abnormality, particularly in individuals with severe/critical COVID-19 who were older. Liver function should be monitored carefully during infection, with judicious use of hepatotoxic agents where possible and avoidance of prolonged hypotension to minimize liver injury in older patients.

Methods: The No. 2 People's Hospital of Fuyang City in China has admitted a total of 159 patients with confirmed COVID-19 since the outbreak from January 2020 to March 2020. We analyzed the incidence of liver function test (LFT) abnormality in these patients with confirmed COVID-19 infection.

\section{INTRODUCTION}

Coronavirus disease 2019 (COVID-19) is a novel infectious disease caused by the severe acute respiratory syndrome coronavirus 2 (SARS coronavirus 2 or SARS-CoV-2) [1-5]. The COVID-19 outbreak was first described in November/December 2019 in China, and has since spread to over 180 countries around the world [6-10]. Due to this rapid spread and severity of the illness, the World Health Organization characterized
COVID-19 as a pandemic [11-13]. COVID-19 continues to be a serious threat to public health worldwide, with a global morality rate of $5.15 \%$ as of June $24^{\text {th }}$ 2020 [10]. However, the mortality rate has varied significantly across regions, ranging from low rates in Qatar $(0.11 \%)$, Russia (1.40\%) and South Africa $(1.98 \%)$, to intermediate rates in India $(3.17 \%)$, Germany (4.63\%), Iran (4.70\%), China (5.48\%) and the United States $(5.16 \%)$, to very high rates in Spain $(11.48 \%)$, the United Kingdom (13.98\%), Italy 
(14.52\%), France (15.03\%) and Belgium (15.97\%) (see the Coronavirus Resource Centre or the latest worldwide data [10, 14]). COVID-19 most commonly causes fever, cough, shortness of breath, myalgia, fatigue, and sore throat [1], ranging from mild in severity to severe, with around a quarter requiring intensive care admission in the largest case series to date $[1,15]$. Asymptomatic infection with confirmed transmission and atypical presentations with abdominal pain, nausea, vomiting and diarrhea have also been reported [15]. However, the frequency of liver dysfunction in COVID-19 infection has not been well described, and in particular have been difficult to interpret due to co-administration of hepatotoxic agents and varied timing of liver function abnormality in the course of the illness and across age groups [16-18]. In this brief report, we sought to analyze the association between COVID-19 infection, liver function test (LFT) abnormality and age in the 159 patients hospitalized for confirmed COVID-19 at the No. 2 People's Hospital of Fuyang City, Fuyang, Anhui Province, China.

\section{RESULTS}

\section{Patients}

A total of 159 patients were admitted with confirmed COVID-19 and enrolled in this study. Baseline demographics and patient characteristics according to severity of COVID-19 are presented in Table 1. Overall, the median age was 43 years, and $56.6 \%(90 / 159)$ were male (Table 1). Thirty-four patients $(21.4 \%)$ were classified to have severe or critical illness (SC) and the remaining 125 patients $(78.6 \%)$ were classified to have mild/moderate illness (MM) (Tables 1, 2). In brief, patients in the MM group were significantly younger, had a lower body mass index (BMI), were less likely to have fever, and had a lower heart rate, lower respiratory rate and higher oxygen saturations at admission compared to the SC group (Table 1), reflecting the severity of their COVID-19. There was a significantly higher proportion of patients with underlying chronic hepatitis B virus (HBV) infection in the SC group compared to the MM group (Table 1). There was a significantly higher proportion of patients with hypertension in the SC group compared to the MM group (Table 1). Other comorbidities were similar between both groups. Patients with chronic HBV were treated with entecavir (ETV) if they met the APASL guidelines for HBV treatment [23].

\section{Liver function test abnormality frequency}

Twenty-eight of the 159 (17.6\%) hospitalized patients had LFT abnormality at the time of hospital admission $(\mathrm{n}=19)$, and a further 9 patients $(5.7 \%)$ developed LFT abnormality during the first week of admission. The proportion of patients with LFT abnormality was significantly higher in the SC group compared to the MM group (32.4\% vs $11.6 \%, \mathrm{p}=0.011$, Table 1$)$.

Among patients with LFT abnormality, the median age was significantly higher in the SC group compared to the MM group ( 52 vs 39 years, $\mathrm{p}=0.021$ ). Three patients had a history of chronic HBV infection, 2 of whom were receiving antiviral therapy with ETV (Tables 2, 3). The distribution of comorbidities was similar among the subset of patients with liver function test abnormality in the MM and SC groups, and in particular there was a similar number of patients with chronic HBV and patients receiving ETV in each group (Tables 2, 3 and Figure 1).

\section{Pattern and degree of liver function test abnormality}

We analyzed the components of the LFT panel, including alanine aminotransferase (ALT) and aspartate aminotransferase (AST), which are markers of hepatocellular damage, and gamma-glutamyl transferase (GGT), and alkaline phosphatase (ALP), which are markers of cholestasis, in COVID-19 patients at the time admission (week 0), at 1, 2 and 6 weeks following date of admission as an inpatient or outpatient depending on length of admission. In addition, we analyzed markers of liver synthetic function including total bilirubin (TBIL), and coagulation profiles using the international normalized ratio (INR). We found that there was only a mild to moderate derangement in LFTs in both MM and SC patient groups (Tables 3, 4 and Figures 1,2), with a mixed pattern of both hepatocellular injury and cholestasis (GGT elevations observed but no changes in ALP were observed), without significant liver synthetic dysfunction.

In more detail, the majority of patients had ALT, AST and GGT levels below 5 times the ULN (Table 4 and Figure 2). In the SC group, 4 (36.4\%) patients had an ALT 1-2x ULN, 4 (36.4\%) patients had an ALT 2-5x ULN, and $3(27.3 \%)$ patients had an elevated ALT $>5 x$ ULN. In the MM group, 9 (52.9\%) patients had an ALT 1-2x ULN, 7 (41.2\%) patients had an ALT 2-5x ULN, and $1(5.9 \%)$ patient had an ALT $>5 x$ ULN. AST was abnormal in $8 \mathrm{SC}$ patients and $7 \mathrm{MM}$ patients with LFT abnormalities. In the SC group, 4 (50\%) patients had an AST of 1-2x ULN, 2 (25\%) patients had AST 2-5x ULN, and $2(25 \%)$ patients had an AST greater than 5 ULN (Table 4 and Figure 2). A total of $7(100 \%)$ patients had an AST 1-2x ULN in the MM group, and no elevations $>2 \mathrm{x}$ ULN were noted in this group (Table 4 and Figure 2). Median ALT and AST values failed to reach statistical significance between the SC and MM groups (Table 4). GGT levels were abnormal in $10 \mathrm{SC}$ 
Table 1. Comparison of baseline demographics and clinical characteristics between SC and MM groups. Values are expressed as median (interquartile range (IQR), 25-75\%). P value is the comparison between severe/critical (SC) and mild/moderate (MM) patients. ${ }^{*} \mathrm{P}<0.05,{ }^{*} \mathrm{P}<0.01, * * * \mathrm{P}<0.001$.

\begin{tabular}{lccc}
\hline Characteristic & SC & MM & P value \\
\hline Total number (n, \%) & $34(21.4 \%)$ & $125(78.6 \%)$ & \\
with liver function test abnormality (n, \%) & $11(32.4 \%)$ & $17(11.6 \%)$ & 0.011 \\
Age (years) (median, IQR) & $49.5(42.5-65.3)$ & $41.0(29.0-50.0)$ & $<0.0001$ \\
Male gender (n, \%) & $23(67.6 \%)$ & $67(53.6 \%)$ & 0.143 \\
Fever (n, \%) & $34(100 \%)$ & $84(67.2 \%)$ & $<0.0001$ \\
Temperature ( ${ }^{\text {C) }}$ (Median, IQR) & $37.1(36.8-37.9)$ & $36.8(36.5-37.5)$ & 0.014 \\
Heart rate (beats / minute) (Median, IQR) & $96(78-102)$ & $84(80-91)$ & 0.039 \\
Blood Pressure (mmHg) (Median, IQR) & $130(116-142) /$ & $128(119.5-140) /$ & $0.671 /$ \\
Respiratory rate (breaths / minute) (Median, IQR) & $84(73-93)$ & $85(75.5-92)$ & 0.711 \\
Oxygen saturation (\%) (Median, IQR) & $20(19-23)$ & $20(19-21.5)$ & 0.031 \\
Treatment with lopinavir/ritonavir (n, \%) & $91.5(89.5-94.3)$ & $98(97-98)$ & $<0.0001$ \\
Treatment with lopinavir/ritonavir and & $30(88.2 \%)$ & $109(87.2 \%)$ & 0.798 \\
hydroxychloroquine (n, \%) & & & \\
Body mass index (kg/m $\mathbf{2}^{\mathbf{2}}$ (Median, IQR) & $1(2.9 \%)$ & $15(12 \%)$ & 0.07 \\
\hline Comorbidities & $25.8(23.4-27.6)$ & $24.2(22.1-26.1)$ & 0.022 \\
\hline Chronic hepatitis B virus (HBV) & $\mathbf{S C}$ & $\mathbf{M M}$ & $\mathbf{P ~ v a l u e}$ \\
Chronic HBV receiving entecavir & 9 & 3 & $<0.0001$ \\
HBV-related cirrhosis & 1 & 2 & 0.517 \\
HBV cirrhosis & 0 & 0 & $\mathrm{a} / \mathrm{n}$ \\
Hypertension & 0 & 0 & $\mathrm{a} / \mathrm{n}$ \\
Diabetes & 13 & 11 & $<0.0001$ \\
Coronary heart disease & 4 & 10 & 0.492 \\
Fatty liver & 3 & 0 & 0.009 \\
Other & 1 & 1 & 0.321 \\
\hline & 9 & 1 & $<0.0001$ \\
\hline
\end{tabular}

Table 2. Comparison of baseline demographics and clinical characteristics between SC and MM groups in the subset with liver function test abnormality.

\begin{tabular}{lccc}
\hline Characteristic & SC & MM & P value \\
\hline Number (n, \%) & $11(32.4 \%)$ & $17(11.6 \%)$ & 0.011 \\
Age (years) (Median, IQR) & $52(40-63)$ & $39(30-47.0)$ & 0.021 \\
Male gender $(\mathbf{n}, \mathbf{\%})$ & $9(81.8 \%)$ & $11(64.7 \%)$ & 0.328 \\
Body mass index $\left(\mathbf{k g} / \mathbf{m}^{2}\right)$ (Median, IQR) & $26.2(25.7-27.0)$ & $24.5(22.9-26.1)$ & 0.120 \\
\hline Comorbidities & SC & MM & P value \\
\hline Chronic hepatitis B virus & $2(1$ on ETV) & $1(1$ on ETV) & 0.543 \\
Hepatitis B virus related cirrhosis & 0 & 0 & a/n \\
Hypertension & 3 & 1 & 0.269 \\
Diabetes & 1 & 1 & 1 \\
Other & 2 & 0 & 0.146 \\
\hline The number of comorbidities & SC & MM & P value \\
\hline One & 1 & 3 & 1 \\
Two & 3 & 0 & 0.05 \\
Three & 1 & 0 & 0.393 \\
\hline
\end{tabular}

Values are expressed as median (interquartile range (IQR), 25-75\%). P value is the comparison between severe/critical (SC) and mild/moderate $(\mathrm{MM})$ patients. ${ }^{*} \mathrm{P}<0.05$. ETV = entecavir. 
Table 3. Comparison of liver function test parameters between MM and SC group patients with abnormal liver function tests (Table 3-1) and normal liver function tests (Table 3-2).

Table 3-1. Patients with abnormal liver function within 1 week of admission.

\begin{tabular}{|c|c|c|c|c|c|c|c|c|c|c|c|c|c|}
\hline & \multicolumn{4}{|c|}{ Week 0} & \multicolumn{3}{|c|}{ Week 1} & \multicolumn{3}{|c|}{ Week 2} & \multicolumn{3}{|c|}{ Week 6} \\
\hline & NRR & $\mathrm{SC} n=11$ & MM n=17 & $\begin{array}{c}\mathbf{P} \\
\text { value }\end{array}$ & $\mathrm{SC} n=11$ & MM n=17 & $\begin{array}{c}P \\
\text { value }\end{array}$ & $S C n=11$ & MM n=17 & $\begin{array}{c}\mathbf{P} \\
\text { value }\end{array}$ & $\mathrm{SC} n=11$ & MM n=17 & $\begin{array}{c}\mathbf{P} \\
\text { value }\end{array}$ \\
\hline ALT (U/L) & $0-50$ & $\begin{array}{c}69 \\
(27-81)\end{array}$ & $\begin{array}{c}62 \\
(33.0-90.5)\end{array}$ & 0.962 & $\begin{array}{c}70 \\
(49-119)\end{array}$ & $\begin{array}{c}60 \\
(49-106)\end{array}$ & 0.64 & $\begin{array}{c}47 \\
(25-210)\end{array}$ & $\begin{array}{c}41.0 \\
(22-71.5)\end{array}$ & 0.378 & $\begin{array}{c}25.5 \\
(15.5-45.5)\end{array}$ & $\begin{array}{c}42.5 \\
(20.3-49.5)\end{array}$ & 0.291 \\
\hline AST (U/L) & $0-50$ & $\begin{array}{c}46 \\
(30-65)\end{array}$ & $\begin{array}{c}40 \\
(28-52.5)\end{array}$ & 0.423 & $\begin{array}{c}37.50 \\
(25.25-74.0)\end{array}$ & $\begin{array}{c}24.0 \\
(18.0-44.25)\end{array}$ & 0.078 & $\begin{array}{c}34.50 \\
(24.25-38.5)\end{array}$ & $\begin{array}{c}25.0 \\
(21.0-31.5)\end{array}$ & 0.128 & $\begin{array}{c}21.5 \\
(17.8-25.8)\end{array}$ & $\begin{array}{c}23.5 \\
(20-29)\end{array}$ & 0.178 \\
\hline GGT (U/L) & $10-60$ & $\begin{array}{c}59 \\
(21-130)\end{array}$ & $\begin{array}{c}35 \\
(21-108.5)\end{array}$ & 0.48 & $\begin{array}{c}96 \\
(55-114)\end{array}$ & $\begin{array}{c}48 \\
(24-99)\end{array}$ & 0.082 & $\begin{array}{c}66 \\
(41.5-166.5)\end{array}$ & $\begin{array}{c}40 \\
(22.5-79)\end{array}$ & 0.217 & $\begin{array}{c}49.5 \\
(23-87.5)\end{array}$ & $\begin{array}{c}34 \\
(22.3-73.5)\end{array}$ & 0.752 \\
\hline $\begin{array}{l}\text { TBIL } \\
(\mu \mathrm{mmol} / \mathrm{L})\end{array}$ & $0-26$ & $\begin{array}{c}13.40 \\
(8.6-33.1)\end{array}$ & $\begin{array}{c}11.5 \\
(7.2-15.5)\end{array}$ & 0.279 & $\begin{array}{c}13.4 \\
(8.6-33.1)\end{array}$ & $\begin{array}{c}11.8 \\
(8.5-15.3)\end{array}$ & 0.264 & $\begin{array}{c}10.9 \\
(7.8-18.4)\end{array}$ & $\begin{array}{c}7.6 \\
(6.3-12.6)\end{array}$ & 0.115 & $\begin{array}{c}9.4 \\
(5.6-16.9)\end{array}$ & $\begin{array}{c}12 \\
(9.5-13.5)\end{array}$ & 0.562 \\
\hline INR & $\begin{array}{c}0.94- \\
1.30\end{array}$ & $\begin{array}{c}1 \\
(0.94-1.11)\end{array}$ & $\begin{array}{c}0.98 \\
(0.91-1.12)\end{array}$ & 0.925 & $\begin{array}{c}0.93 \\
(0.85-0.98)\end{array}$ & $\begin{array}{c}0.92 \\
(0.85-0.95)\end{array}$ & 0.744 & $\begin{array}{c}0.92 \\
(0.9-0.99)\end{array}$ & $\begin{array}{c}0.88 \\
(0.87-0.93)\end{array}$ & 0.176 & $\begin{array}{c}0.93 \\
(0.88-0.97)\end{array}$ & $\begin{array}{c}0.91 \\
(0.88-0.95)\end{array}$ & 0.735 \\
\hline
\end{tabular}

Normal reference range (NRR), alanine aminotransferase (ALT), aspartate aminotransferase (AST), gamma-glutamyl transferase (GGT), alkaline phosphatase (ALP), total bilirubin (TBIL), and international normalized ratio (INR).

Table 3-2. Patients with normal liver function within 1 week of admission.

\begin{tabular}{|c|c|c|c|c|c|c|c|c|c|c|c|c|c|}
\hline & \multicolumn{4}{|c|}{ Week 0} & \multicolumn{3}{|c|}{ Week 1} & \multicolumn{3}{|c|}{ Week 2} & \multicolumn{3}{|c|}{ Week 6} \\
\hline ALT (U/L) & $0-50$ & $\begin{array}{c}25 \\
(18-33)\end{array}$ & $\begin{array}{c}23 \\
(13-36)\end{array}$ & 0.515 & $\begin{array}{c}22 \\
(18-32)\end{array}$ & $\begin{array}{c}19 \\
(13-34.5)\end{array}$ & 0.632 & $\begin{array}{c}30 \\
(22-47.5)\end{array}$ & $\begin{array}{c}28.5 \\
(15-44)\end{array}$ & 0.206 & $\begin{array}{c}18 \\
(13.5-33.8)\end{array}$ & $\begin{array}{c}26 \\
(15-40)\end{array}$ & 0.25 \\
\hline AST (U/L) & $0-50$ & $\begin{array}{c}28 \\
(23-30)\end{array}$ & $\begin{array}{c}25 \\
(19-31)\end{array}$ & 0.091 & $\begin{array}{c}24 \\
(19-26)\end{array}$ & $\begin{array}{c}21 \\
(18-24)\end{array}$ & 0.197 & $\begin{array}{c}21 \\
(18-28.5)\end{array}$ & $\begin{array}{c}20 \\
(16-26)\end{array}$ & 0.394 & $\begin{array}{c}19 \\
(16-26)\end{array}$ & $\begin{array}{c}23 \\
(18-30)\end{array}$ & 0.07 \\
\hline GGT (U/L) & $10-60$ & $\begin{array}{c}23 \\
(16-33)\end{array}$ & $\begin{array}{c}26 \\
(15-41)\end{array}$ & 0.934 & $\begin{array}{c}23 \\
(18-29)\end{array}$ & $\begin{array}{c}22 \\
(15-38)\end{array}$ & 0.55 & $\begin{array}{c}30 \\
(21-46.5)\end{array}$ & $\begin{array}{c}26.5 \\
(16.8-53)\end{array}$ & 0.416 & $\begin{array}{c}21 \\
(15.5-26.8)\end{array}$ & $\begin{array}{c}29 \\
(17-46)\end{array}$ & 0.099 \\
\hline $\begin{array}{l}\text { TBIL } \\
(\mu \mathrm{mmol} / \mathrm{L})\end{array}$ & $0-26$ & $\begin{array}{c}11.4 \\
(7.2-15.2)\end{array}$ & $\begin{array}{c}9.9 \\
(7.0-15.3)\end{array}$ & 0.495 & $\begin{array}{c}13.6 \\
(8.1-17.7)\end{array}$ & $\begin{array}{c}11.9 \\
(9.4-15.6)\end{array}$ & 0.951 & $\begin{array}{c}9.8 \\
(6.4-19.3)\end{array}$ & $\begin{array}{c}7.5 \\
(5.9-10.2)\end{array}$ & 0.034 & $\begin{array}{c}11 \\
(6.5-13)\end{array}$ & $\begin{array}{c}10.5 \\
(8.4-14.1)\end{array}$ & 0.562 \\
\hline INR & $0.94-1.30$ & $\begin{array}{c}1.01 \\
(0.95-1.07)\end{array}$ & $\begin{array}{c}0.98 \\
(0.94-1.07)\end{array}$ & 0.702 & $\begin{array}{c}0.95 \\
(0.93-1.01)\end{array}$ & $\begin{array}{c}0.93 \\
(0.88-1.0) \\
\end{array}$ & 0.123 & $\begin{array}{c}0.95 \\
(0.88-1.08)\end{array}$ & $\begin{array}{c}0.93 \\
(0.9-0.95)\end{array}$ & 0.505 & $\begin{array}{c}0.91 \\
(0.87-0.97)\end{array}$ & $\begin{array}{c}0.91 \\
(0.89-0.92)\end{array}$ & 0.91 \\
\hline
\end{tabular}

Values are expressed as median (interquartile range (IQR), 25-75\%). P value is the comparison between Severe, Critical (SC) and Mild, Moderate (MM) group patients.

patients and $17 \mathrm{MM}$ patients with LFT abnormalities (Table 4). In the SC group, $6(60 \%)$ patients had elevated GGT levels 1-2x ULN, and 4 (40\%) patients had elevated GGT levels 2-5x ULN. In the MM group, $14(82.4 \%)$ patients had elevated GGT levels 1-2x ULN, and $3(17.6 \%)$ patients had elevated GGT levels 2-5x ULN (Table 4 and Figure 2). Only 1 patient had an abnormal ALP in MM group (1-2x ULN), and no patients had abnormal ALP levels in the SC group (Table 4 and Figure 2). Only 3 patients had an elevated TBIL in the SC group; 1 patient had a TBIL 1-2x ULN, and 2 patients had a TBIL 2-5x ULN (all 3 patients had an elevated ALT, but normal ALP and INR) (Table 4 and Figure 2). TBIL elevation was not observed in the MM group. All patients had a normal INR (Tables 3, 4 and Figures 1,2). Patients who experienced elevations in ALT above 2x ULN received glycyrrhizin therapy, which is routinely used as a hepatoprotective agent in our institution. LFT abnormalities recovered in all patients, and median time to normalization was 10 days.

In our case series, the most significantly elevated ALT was observed in a patient with chronic HBV who was treatment-naïve, where the peak ALT was $414 \mathrm{U} / \mathrm{L}$, with an AST of $309 \mathrm{U} / \mathrm{L}$, GGT of $290 \mathrm{U} / \mathrm{L}$, ALP of 86 $\mathrm{U} / \mathrm{L}$, and an elevated TBIL of $70.5 \mu \mathrm{mol} / \mathrm{L}$, but normal INR (1.08). Further characterization of the HBV revealed the patient was $\mathrm{HBsAg}$ positive, $\mathrm{HBeAg}$ positive and the HBV DNA was elevated at 22,800 $\mathrm{IU} / \mathrm{mL}$. Given the significant elevation in HBV DNA, 
the treating clinician felt that the LFT abnormalities were more likely attributable to their chronic HBV rather than COVID-19, and entecavir was commenced, in addition to glycyrrhizin therapy for 13 days. The LFTs normalized over the following 13 days in this patient.

\section{DISCUSSION}

COVID-19 can lead to symptoms including fever, cough, fatigue, shortness of breath and myalgias. In more severe disease, COVID-19 may cause significant shortness of breath, hypoxia and respiratory failure, as well as radiographic features of pneumonia and/or other lung infiltrates. Although the lung is the primary target organ of SARS-CoV-2, confirmed at autopsy and characterized by an inflammatory reaction in the deep airway and alveolar injury [24], there are several reports that COVID-19 may also cause liver function test abnormality [1, 16, 17, 25], however these case series are difficult to interpret due to frequent coadministration of hepatotoxic agents such as lopinavir /ritonavir and other conditions that may lead to liver injury such as ischaemic hepatitis from severe and/or prolonged hypotension/shock. In this report, we observed that LFT abnormality is frequent in COVID-19
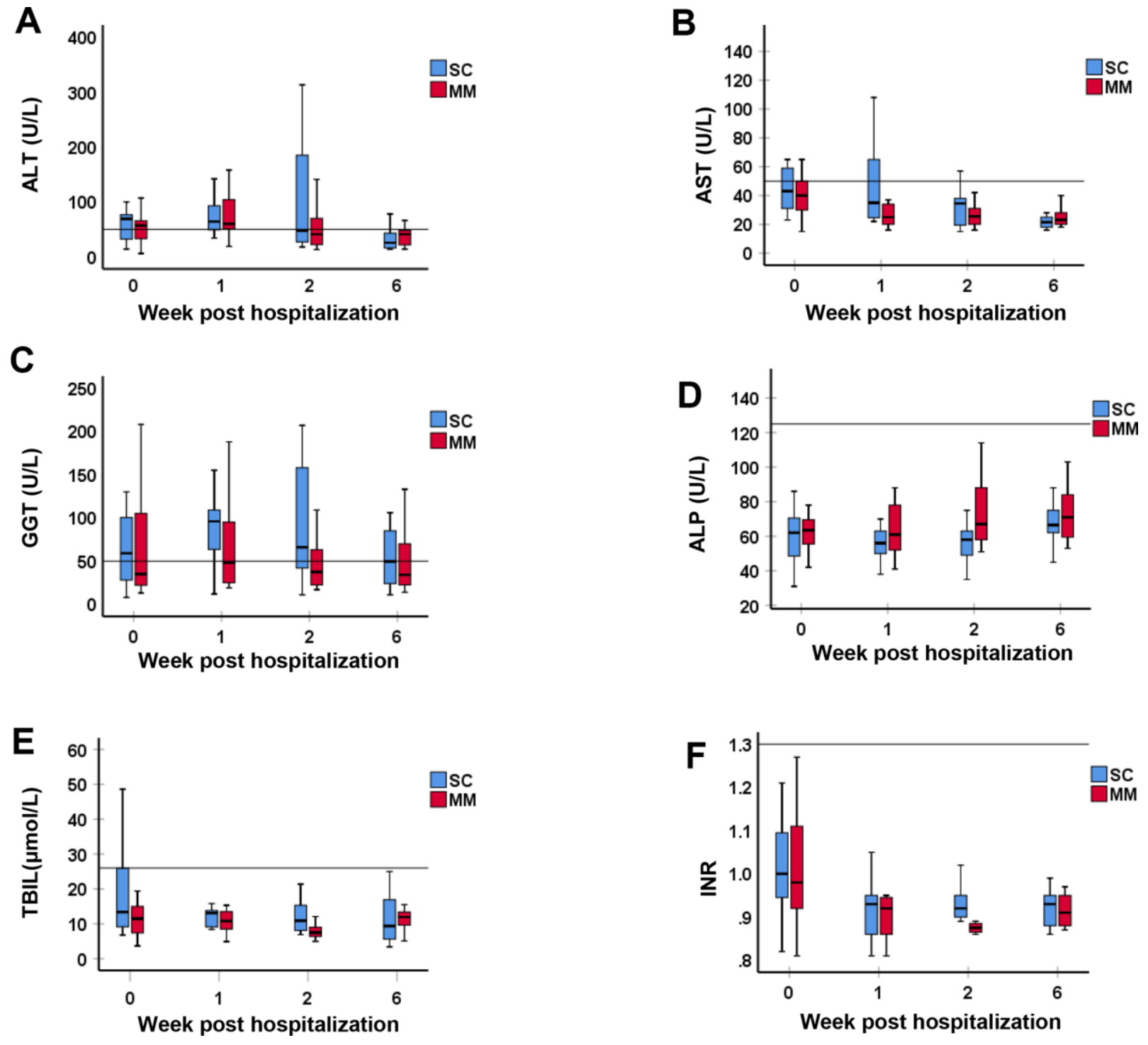

Figure 1. Comparison of liver function test between MM and SC patient groups with liver function test abnormality. The liver function tests including (A) ALT, (B) AST, (C) GGT, (D) ALP, (E) TBIL, and (F) INR, were compared between MM and SC patient groups with liver function test abnormality at Week 0, 1, 2 and 6 post hospitalization for COVID-19. Values are expressed as median (interquartile range (IQR), 25-75\%). The horizontal line in each panel is the upper limit of normal (ULN) for each parameter. There was no statistically significant difference in any of the LFT or INR parameters between SC and MM patients. 
Table 4. Degree of liver function test abnormality in SC and MM groups in the subset with liver abnormality.

\begin{tabular}{lccccccccc}
\hline & \multicolumn{2}{c}{$\mathbf{1 - 2}$ ULN } & \multirow{2}{*}{ P value } & \multicolumn{2}{c}{$\mathbf{2 - 5}$ ULN } & \multirow{2}{*}{ P value } & \multicolumn{2}{c}{$>$ 5ULN } & \multirow{2}{*}{ P value } \\
\cline { 2 - 3 } & SC & MM & & SC & MM & & SC & MM & \\
\hline ALT (n, \%) & $4(11,36.4 \%)$ & $9(17,52.9 \%)$ & 0.057 & $4(11,36.4 \%)$ & $7(17,41.2 \%)$ & 0.799 & $3(11,27.3 \%)$ & $1(17,5.9 \%)$ & 0.269 \\
AST (n, \%) & $4(8,50 \%)$ & $7(7,100 \%)$ & 0.799 & $2(8,25 \%)$ & 0 & 0.543 & $2(8,25 \%)$ & 0 & 0.146 \\
GGT (n, \%) & $6(10,60 \%)$ & $14(17,82.4 \%)$ & 0.112 & $4(10,40 \%)$ & $3(17,17.6 \%)$ & 0.264 & 0 & 0 & $\mathrm{a} / \mathrm{n}$ \\
ALP (n, \%) & 0 & $1(100 \%)$ & 0.206 & 0 & 0 & $\mathrm{a} / \mathrm{n}$ & $\mathbf{0}$ & $\mathbf{0}$ & $\mathrm{a} / \mathrm{n}$ \\
TBIL (n, \%) & $1(3,33.3 \%)$ & 0 & 0.206 & $2(3,66.7 \%)$ & 0 & 0.068 & 0 & 0 & $\mathrm{a} / \mathrm{n}$ \\
INR & 0 & 0 & $\mathrm{a} / \mathbf{n}$ & 0 & 0 & $\mathrm{a} / \mathrm{n}$ & 0 & 0 & $\mathrm{a} / \mathrm{n}$ \\
\hline
\end{tabular}

Alanine aminotransferase (ALT), aspartate aminotransferase (AST), gamma-glutamyl transferase (GGT), alkaline phosphatase (ALP), total bilirubin (TBIL), and international normalized ratio (INR).

Values are expressed as median (interquartile range (IQR), 25-75\%). P value is the comparison between severe/critical (SC) and mild/moderate (MM) patients.

patients hospitalized at the No. 2 People's Hospital of Fuyang City, with an overall frequency of LFT abnormality of $17.6 \%$ in the 159 patients with confirmed COVID-19. In addition, our study demonstrates that

A
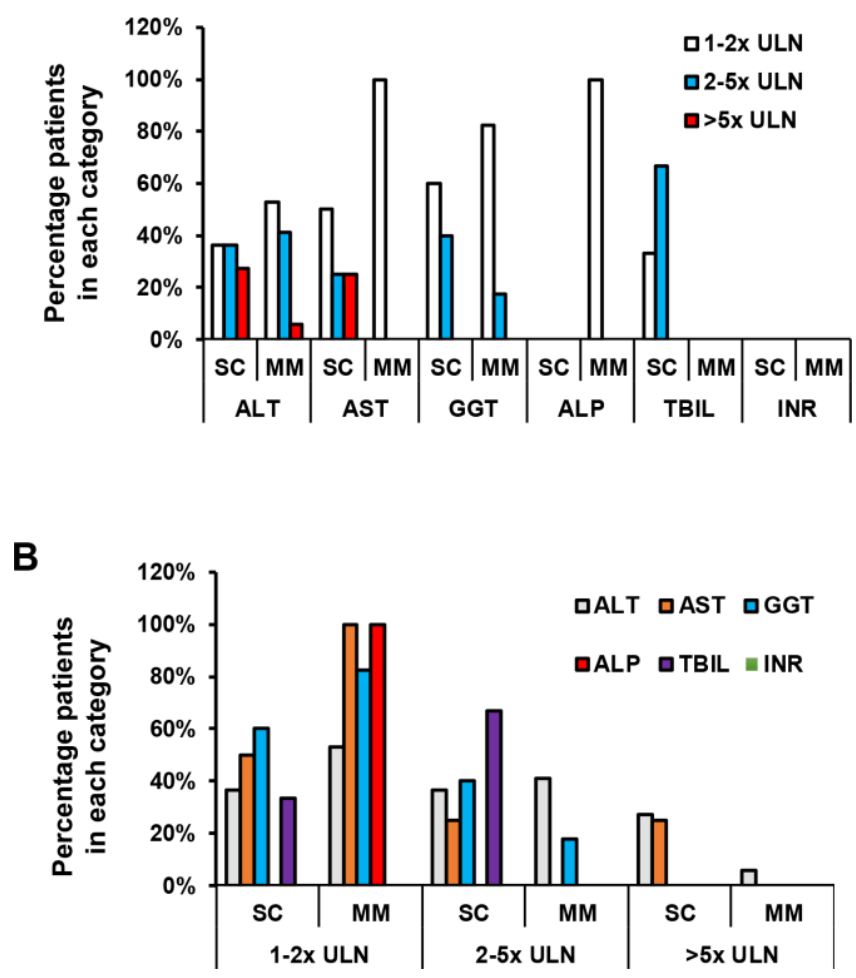

Figure 2. Degree of liver function test abnormality in SC and $\mathrm{MM}$ groups in the subset with liver function test abnormality. (A) Comparison of liver function abnormality between SC and MM groups with liver abnormality. (B) Comparison of liver function subset between SC and MM groups with liver abnormality. There was no statistically significant difference in the degree of LFT abnormality between SC and MM patients. older patients are more likely to develop more severe COVID-19, which has been observed throughout the world, and are also more likely to develop LFT abnormality [18]. Furthermore, we observed a significantly higher proportion of patients with liver function test abnormality in the SC group compared to the $\mathrm{MM}$ group, suggesting a greater frequency of liver dysfunction in the SC group. These findings are consistent with other reports of COVID-19 in China $[15,25]$, and importantly demonstrates frequent LFT abnormality prior to the administration of potentially hepatotoxic agents. Our study therefore offers some interesting findings of liver involvement during COVID19 infection.

Liver dysfunction has been seen during other respiratory virus pandemics, although the incidence of LFT dysfunction was more severe with pandemic A/H1N1 influenza in 2009 than during this current COVID-19 outbreak [26], whereby serum levels of AST, ALT, and GGT were significantly higher in the A/H1N1 influenza than observed in COVID-19. Interestingly, abnormalities in serum liver enzymes were strongly correlated with hypoxemia in the A/H1N1 influenza pandemic, suggesting that influenza itself may in some way mediate the hepatotoxicity [26]. When comparing liver function test parameters between our SC and MM COVID-19 patients, we found that the SC patients had a higher incidence of liver injury to MM patients, however the pattern and degree of LFT abnormality was not significantly different between the two groups with regards to the proportion of patients with LFT abnormalities 1-2x ULN, 2-5x ULN and $>5 x$ ULN. We did observe that median ALT and AST values were numerically higher in SC patients compared to MM patients, with median ALT values above the ULN in the SC group, however this failed to reach statistical significance. These findings indicate that COVID-19 is associated with mild to moderate liver function test abnormalities with a mixed picture of liver injury, 
particularly in SC patients. However, accompanying significant liver synthetic function compromise or liver failure were not observed in this cohort. In addition, our findings indicate that older patients are not only more likely to develop more severe COVID-19 but are also at greater risk of liver function abnormality.

It should be noted that the vast majority of the patients enrolled in this study received lopinavir/ritonavir with or without hydroxychloroquine as potential antiviral agents. Lopinavir/ritonavir is a well described to cause drug-induced liver injury (DILI). Therefore, we designed our study to restrict the definition of LFT abnormality to the first week following admission in order to limit potential confounding from hepatotoxicity from lopinavir/ritonavir. However, liver function parameters did not significantly change from baseline or week 1 to week 2 , indicating that lopinavir/ritonavir-induced DILI does not explain our findings.

There are increasing reports of COVID-19 induced liver dysfunction in China, where mild elevations in liver functions tests have also been described $[1,15$, 27, 28]. However, the mechanism by which COVID19 induces liver function abnormality is not well characterized. There is much speculation regarding potential mechanisms, which include direct liver injury from SARS-CoV-2 infection of hepatocytes, cytokine storm syndrome, DILI and ischaemic hepatitis. We speculate that hepatocytes could be infected given SARS caused by SARS-CoV-1, another coronavirus similar to SARS-CoV-2, as SARS-CoV-1 RNA was detected in liver tissue from patients with SARS, although viral inclusions were not seen on electron microscopy [29].

Interestingly, non-specific histological features of microvascular steatosis and mild lobular and portal activity has been observed in the liver at autopsy in a patient who died of severe COVID-19 [27]. However, viral inclusions were not identified in liver tissue at autopsy and therefore it is unclear if these changes were related to direct viral infection of the liver by SARSCoV-2, DILI, or even due to pre-existing fatty liver disease, although it should be noted that viral inclusions were also not seen in lung tissue (the primary target organ of COVID-19) in this patient. Another potential mechanism that has been considered is the effect of COVID-19 induced cytokine storm syndrome (CSS) on liver injury, but without strong evidence supporting this hypothesis. Liver damage may also be influenced by underlying liver diseases, such as chronic HBV and fatty liver disease, or as a result of pneumoniaassociated hypoxia or ischaemic hepatitis from prolonged hypotension. These data highlight that further studies are required to elucidate the mechanism(s) of liver impairment in COVID-19.

In summary, we found that COVID-19 associated liver function test abnormality is more common in patients with severe or critical presentations of COVID-19, as well as older patients. Although the degree of COVID19 induced liver function abnormality is relatively mild to moderate in our cohort without evidence of significant liver synthetic dysfunction or liver failure, it highlights the frequent incidence of LFT abnormalities in patients with COVID-19, which has implications for the management of these patients in order to preserve liver function with consideration of co-administration of hepatoprotective agents and to minimize exposure to hepatotoxic events, particularly in patients with underlying liver disease and older age. Our study adds to the growing body of evidence that SARS-CoV-2 is associated with liver function test abnormality, and particularly in older patients $[18,30,31]$. A more detailed understanding of the underlying mechanisms of liver injury from SAR-CoV-2, as well as viral pathogenesis and antiviral responses to COVID-19 are therefore required in order to best optimize older age patient outcomes.

\section{MATERIALS AND METHODS}

\section{Patients and study design}

As of March $4^{\text {th }}, 2020$, the No. 2 People's Hospital of Fuyang City has admitted 159 patients (including 4 patients transferred from Bozhou City, Anhui Province) with confirmed COVID-19 since the outbreak of the disease in Anhui Province in January 2020. No COVID19 related deaths have been recorded in this hospital. The majority of the patients enrolled in this study received lopinavir/ritonavir with or without hydroxychloroquine for antiviral therapy. All COVID-19 patients were diagnosed, classified and treated according to the guidelines of the Pneumonia Treatment Plan for the Novel Coronavirus Infection, National Health and Health Commission of the people's Republic of China (Version 1-6) [19-22]. Patients with confirmed COVID-19 were included, and classification of severity criteria was as follows: 1) mild: mild clinical symptoms without pneumonia on imaging; 2) moderate: fever, respiratory tract infection symptoms with pneumonia on imaging; 3) severe: confirmed COVID19 with one or more of the following 3 features: (a) breathing distress, respiratory rate $\geq 30$ breaths/minute, (b) oxygen saturation $\leq 93 \%$ on room air, or (c) oxygenation index $\leq 300 \mathrm{mmHg}$; 4) critical: confirmed COVID-19 with one or more of the following 3 features: (a) respiratory failure requiring mechanical ventilation, (b) coma, (c) combined organ failure 
requiring ICU monitoring (for example, dysfunction/ failure of more than 2 organ systems that requires ICU support). Exclusion criteria included patients with respiratory symptoms that repeatedly tested negative for COVID-19 and did not have pneumonia on imaging, and those with new onset of liver dysfunction one week after hospitalization. This time point was chosen in order to exclude patients that may have developed abnormal LFTs from another cause such as ischaemic hepatitis from prolonged hypotension/shock or druginduced liver injury. In this report, we sought to analyze the frequency of LFT abnormality and liver dysfunction in COVID-19 patients, and specifically to compare the incidence of LFT abnormality and liver dysfunction between COVID-19 patients with mild or moderate illness (MM group) and those with severe or critical illness (SC group). LFT abnormality is defined as any parameter of the liver enzyme panel greater than the upper limit of normal (ULN). We also evaluated liver synthetic function abnormality with International Normalized Ratio (INR) and elevated total bilirubin (TBIL).

\section{Ethics approval and consent to participate}

This study was approved by the Ethics Review Committee of the No. 2 People's Hospital of Fuyang City (reference number: 2020006) and was conducted in accordance with the ethical standards of the institutional and national research committees, and with the 1964 declaration of Helsinki. This study was registered at the Chinese Clinical Trial Registry (registration number ChiCTR2000031620).

\section{COVID-19 detection and laboratory parameter testing}

Nasopharyngeal aspirates and sputum from patients with suspected COVID-19 were used for COVID-19 testing. COVID-19 RNA was detected by using realtime quantitative PCR (qPCR) (Shanghai BioGerm Medical Biotechnology Co., Shanghai, China). Liver function was measured by using the Hitachi 7600 fully automatic biochemical analyzer. The complete blood count was measured by using the SYSMEX CA5100 automatic clotting analyzer (Siemens Healthcare, Erlangen, Germany). Internationalized Normalized Ratio (INR) was calculated based on the prothrombin time (PT) test result.

\section{Statistical analyses}

Data were analyzed using SPSS Statistics v25.0 (Armonk, New York, USA). Continuous data were expressed as medians with interquartile range, and categorical data as frequencies. Groups were compared using the Mann-Whitney $\mathrm{U}$ test, and the correlations between clinical, laboratory parameter were evaluated using the two-tailed chi-squared test.

\section{AUTHOR CONTRIBUTIONS}

Shasha Li, Jinsong Li, Tuo Shao, Xiuyong Li, Jacinta A. Holmes, Wenyu Lin and Mingfeng Han designed the research study, analyzed and interpreted the data, and wrote the manuscript. Shasha $\mathrm{Li}$, Jinsong $\mathrm{Li}$, Zhenhua Zhang, Lin Tan, Ming Li, Xiuyong Li and Mingfeng Han were involved in diagnosis and treatment of patients, recruiting patients and collection of clinical data. All authors were involved in critical appraisal of the manuscript and approved the final version of the manuscript.

\section{CONFLICTS OF INTEREST}

The authors have declared that no conflicts of interest exist.

\section{FUNDING}

This study was funded in part by grant of Natural Science Foundation of China (NSFC 81871661 to Wenyu Lin), the COVID-19 Urgent Research Grant of Fuyang City Department of Science and Technology (FK20202801 to Xiuyong Li).

\section{REFERENCES}

1. Chen N, Zhou M, Dong X, Qu J, Gong F, Han Y, Qiu Y, Wang J, Liu Y, Wei Y, Xia J, Yu T, Zhang X, Zhang L. Epidemiological and clinical characteristics of 99 cases of 2019 novel coronavirus pneumonia in Wuhan, China: a descriptive study. Lancet. 2020; 395:507-13. https://doi.org/10.1016/S0140-6736(20)30211-7 PMID:32007143

2. Menachery VD, Schäfer $A$, Burnum-Johnson $K E$, Mitchell HD, Eisfeld AJ, Walters KB, Nicora CD, Purvine SO, Casey CP, Monroe ME, Weitz KK, Stratton KG, Webb-Robertson BM, et al. MERS-CoV and H5N1 influenza virus antagonize antigen presentation by altering the epigenetic landscape. Proc Natl Acad Sci USA. 2018; 115:E1012-21. https://doi.org/10.1073/pnas.1706928115 PMID:29339515

3. Song Z, Xu Y, Bao L, Zhang L, Yu P, Qu Y, Zhu H, Zhao W, Han $Y$, Qin C. From SARS to MERS, thrusting coronaviruses into the spotlight. Viruses. 2019; 11:59. https://doi.org/10.3390/v11010059 PMID:30646565

4. The Lancet. Emerging understandings of 2019-nCoV. Lancet. 2020; 395:311. 
https://doi.org/10.1016/S0140-6736(20)30186-0 PMID:31986259

5. Yin $Y$, Wunderink RG. MERS, SARS and other coronaviruses as causes of pneumonia. Respirology. 2018; 23:130-37. https://doi.org/10.1111/resp.13196 PMID:29052924

6. Ki M, and Task Force for 2019-nCoV. Epidemiologic characteristics of early cases with 2019 novel coronavirus (2019-nCoV) disease in Korea. Epidemiol Health. 2020; 42:e2020007.

https://doi.org/10.4178/epih.e2020007 PMID:32035431

7. Giovanetti $M$, Benvenuto $D$, Angeletti $S$, Ciccozzi $M$. The first two cases of 2019-nCoV in Italy: where they come from? J Med Virol. 2020; 92:518-21.

https://doi.org/10.1002/jmv.25699

PMID: 32022275

8. Chan JF, Yuan S, Kok KH, To KK, Chu H, Yang J, Xing F, Liu J, Yip CC, Poon RW, Tsoi HW, Lo SK, Chan KH, et al. A familial cluster of pneumonia associated with the 2019 novel coronavirus indicating person-to-person transmission: a study of a family cluster. Lancet. 2020; 395:514-23.

https://doi.org/10.1016/S0140-6736(20)30154-9 PMID:31986261

9. Lu H, Stratton CW, Tang YW. Outbreak of pneumonia of unknown etiology in Wuhan, China: the mystery and the miracle. J Med Virol. 2020; 92:401-02. https://doi.org/10.1002/jmv.25678 PMID:31950516

10. Liu RB, Tayal VS, Panebianco NL, Tung-Chen Y, Nagdev A, Shah S, Pivetta E, Henwood PC, Nelson MJ, Moore $\mathrm{CL}$. Ultrasound on the frontlines of COVID-19: report from an international webinar. Acad Emerg Med. 2020; 27:523-26.

https://doi.org/10.1111/acem.14004 PMID:32348585

11. Hui DS, I Azhar E, Madani TA, Ntoumi F, Kock R, Dar O, Ippolito G, Mchugh TD, Memish ZA, Drosten C, Zumla A, Petersen E. The continuing 2019-nCoV epidemic threat of novel coronaviruses to global health - the latest 2019 novel coronavirus outbreak in Wuhan, China. Int J Infect Dis. 2020; 91:264-66.

https://doi.org/10.1016/j.ijid.2020.01.009

PMID:31953166

12. Li $Q$, Guan $X$, Wu $P$, Wang $X$, Zhou $L$, Tong $Y$, Ren $R$, Leung KS, Lau EH, Wong JY, Xing $X$, Xiang $N$, Wu $Y$, et al. Early transmission dynamics in Wuhan, China, of novel coronavirus-infected pneumonia. N Engl J Med. 2020; 382:1199-207.

https://doi.org/10.1056/NEJMoa2001316

PMID:31995857
13. Zhu N, Zhang D, Wang W, Li X, Yang B, Song J, Zhao X, Huang B, Shi W, Lu R, Niu P, Zhan F, Ma X, et al, and China Novel Coronavirus Investigating and Research Team. A novel coronavirus from patients with pneumonia in China, 2019. N Engl J Med. 2020; 382:727-33.

https://doi.org/10.1056/NEJMoa2001017

PMID: $\underline{31978945}$

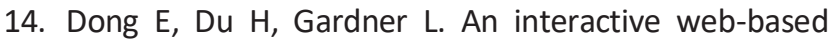
dashboard to track COVID-19 in real time. Lancet Infect Dis. 2020; 20:533-34.

https://doi.org/10.1016/S1473-3099(20)30120-1 PMID:32087114

15. Wang D, Hu B, Hu C, Zhu F, Liu X, Zhang J, Wang B, Xiang $\mathrm{H}$, Cheng $Z$, Xiong $\mathrm{Y}$, Zhao $\mathrm{Y}$, Li Y, Wang $\mathrm{X}$, Peng $Z$. Clinical characteristics of 138 hospitalized patients with 2019 novel coronavirus-infected pneumonia in Wuhan, China. JAMA. 2020; 323:1061-69.

https://doi.org/10.1001/jama.2020.1585

PMID:32031570

16. Cai Q, Huang D, Yu H, Zhu Z, Xia Z, Su Y, Li Z, Zhou G, Gou J, Qu J, Sun Y, Liu Y, He Q, et al. COVID-19: abnormal liver function tests. J Hepatol. 2020; S01688278:30218.

https://doi.org/10.1016/j.jhep.2020.04.006

PMID:32298767

17. Zhang C, Shi L, Wang FS. Liver injury in COVID-19: management and challenges. Lancet Gastroenterol Hepatol. 2020; 5:428-30.

https://doi.org/10.1016/S2468-1253(20)30057-1 PMID:32145190

18. Sargiacomo C, Sotgia F, Lisanti MP. COVID-19 and chronological aging: senolytics and other anti-aging drugs for the treatment or prevention of corona virus infection? Aging (Albany NY). 2020; 12:6511-17.

https://doi.org/10.18632/aging.103001 PMID:32229706

19. Novel coronavirus pneumonia diagnosis and treatment plan (Trial Version Sixth). National Health and Health Commission of the people's Republic of China. 2020; http://www.nhc.gov.cn/yzygi/s7653p/202002/8334a8 326dd94d329df351d7da8aefc2/files/b218cfeb1bc546 39af227f922bf6b817.pdf.

20. Novel coronavirus pneumonia diagnosis and treatment plan (Version Fourth). National Health and Health Commission of the people's Republic of China. 2020; http://www.nhc.gov.cn/iki/s3577/202002/573340613 ab243b3a7f61df260551dd4/files/c791e5a7ea5149f68 Ofdcb34dac0f54e.pdf.

21. Novel coronavirus pneumonia diagnosis and treatment plan (Version Third). National Health and Health Commission of the People's Republic of China. 2020; 
http://www.nhc.gov.cn/jki/s7923/202001/470b12851

3fe46f086d79667db9f76a5/files/8faa1b85841f42e8a0f ebbea3d8b9cb2.pdf.

22. Novel coronavirus pneumonia diagnosis and treatment plan (Revised Version Fifth). National Health and Health Commission of the people's Republic of China. 2020: http://www.nhc.gov.cn/yzygi/s7653p/202002/d202004 b895337e219445f202008d202728fcaf202001e202003e 202013a.shtml.

23. Sarin SK, Kumar M, Lau GK, Abbas Z, Chan HL, Chen CJ, Chen DS, Chen HL, Chen PJ, Chien RN, Dokmeci AK, Gane E, Hou JL, et al. Asian-pacific clinical practice guidelines on the management of hepatitis B: a 2015 update. Hepatol Int. 2016; 10:1-98.

https://doi.org/10.1007/s12072-015-9675-4

PMID:26563120

24. Liu Q, Wang R, Qu G, Wang Y, Liu P, Fei G, Ren L, Zhou $Y$, Liu L. General observation report on the autopsy system of death of new coronavirus pneumonia. Journal of Forensic Medicine, Chinese. 2020; 36:19-21.

25. Liu C, Jiang ZC, Shao CX, Zhang HG, Yue HM, Chen ZH, Ma BY, Liu WY, Huang HH, Yang J, Wang Y, Liu HY, Xu $D$, et al. [Preliminary study of the relationship between novel coronavirus pneumonia and liver function damage: a multicenter study]. Zhonghua Gan Zang Bing Za Zhi. 2020; 28:107-11.

https://doi.org/10.3760/cma.j.issn.10073418.2020.02.003 PMID:32077660

26. Papic N, Pangercic A, Vargovic M, Barsic B, Vince A, Kuzman I. Liver involvement during influenza infection: perspective on the 2009 influenza pandemic. Influenza Other Respir Viruses. 2012; 6:e2-5. https://doi.org/10.1111/j.1750-2659.2011.00287.x PMID:21951624
27. Xu Z, Shi L, Wang Y, Zhang J, Huang L, Zhang C, Liu S, Zhao P, Liu H, Zhu L, Tai Y, Bai C, Gao T, et al. Pathological findings of COVID-19 associated with acute respiratory distress syndrome. Lancet Respir Med. 2020; 8:420-22.

https://doi.org/10.1016/S2213-2600(20)30076-X

PMID:32085846

28. Guan GW, Gao L, Wang JW, Wen XJ, Mao TH, Peng SW, Zhang T, Chen XM, Lu FM. [Exploring the mechanism of liver enzyme abnormalities in patients with novel coronavirus-infected pneumonia]. Zhonghua Gan Zang Bing Za Zhi. 2020; 28:100-06.

https://doi.org/10.3760/cma.j.issn.1007-

3418.2020.02.002

PMID:32077659

29. Chau TN, Lee KC, Yao H, Tsang TY, Chow TC, Yeung YC, Choi KW, Tso YK, Lau T, Lai ST, Lai CL. SARS-associated viral hepatitis caused by a novel coronavirus: report of three cases. Hepatology. 2004; 39:302-10.

https://doi.org/10.1002/hep.20111

PMID: 14767982

30. Zhang L, Pang $R$, Xue $X$, Bao J, Ye $S$, Dai $Y$, Zheng $Y$, Fu $Q, H u Z, Y i$ Y. anti-SARS-CoV-2 virus antibody levels in convalescent plasma of six donors who have recovered from COVID-19. Aging (Albany NY). 2020; 12:6536-42.

https://doi.org/10.18632/aging.103102

PMID:32320384

31. Yang J, Li H, Hu S, Zhou Y. ACE2 correlated with immune infiltration serves as a prognostic biomarker in endometrial carcinoma and renal papillary cell carcinoma: implication for COVID-19. Aging (Albany NY). 2020; 12:6518-35.

https://doi.org/10.18632/aging.103100

PMID: $\underline{32339157}$ 